\title{
Review Article \\ Gas Phase Growth of Wurtzite ZnS Nanobelts on a Large Scale
}

\author{
Jing Wang, Yang Jiao, Yang Liu, Zhenglin Zhang, Fengyu Qu, and Xiang Wu \\ Key Laboratory for Photonic and Electronic Bandgap Materials, Ministry of Education and College of Chemistry and \\ Chemical Engineering, Harbin Normal University, Harbin 150025, China \\ Correspondence should be addressed to Xiang Wu; wuxiang05@gmail.com
}

Received 15 December 2012; Accepted 26 December 2012

Academic Editor: Xijin Xu

Copyright ( 2013 Jing Wang et al. This is an open access article distributed under the Creative Commons Attribution License, which permits unrestricted use, distribution, and reproduction in any medium, provided the original work is properly cited.

We showed large-scale synthesis of $\mathrm{ZnS}$ nanobelts by simply thermal evaporation of $\mathrm{ZnS}$ powder in the presence of Au catalysts at $1020^{\circ} \mathrm{C}$. Scanning electron microscope (SEM), transmission electron microscope (TEM), and X-ray diffraction (XRD) analyses demonstrated that the as-obtained $\mathrm{ZnS}$ nanobelts possess hexagonal wurtzite structures. The nanobelts have lengths ranging from tens to hundreds of micrometers, thicknesses of tens of nanometers, and widths ranging from hundreds of nanometers to the order of micrometers. The growth process was proposed on the basis of known vapor-liquid-solid (VLS) mechanism. Room temperature photoluminescence measurements showed that the as-synthesized $\mathrm{ZnS}$ nanostructures had a strong green emission bands at a wavelength of $427 \mathrm{~nm}$, which can be attributed to deep-level emissions induced by defects or impurities.

\section{Introduction}

Semiconductor materials have been extensively researched due to their potential applications in optical, photocatalytic, and optoelectronic fields [1-7]. Among them, wide band gap II-VI semiconductors are efficient emitters from blue to UV spectra range and are likely candidates to replace materials like $\mathrm{GaN}$ in light emitting laser diodes [8]. In particular, Zinc sulfide, a direct wide band gap semiconductor $(3.7 \mathrm{eV})$ with exciton binding energy of $40 \mathrm{meV}$ [9], has a high refractive index [10] and a high transmittance in the visible range [11]. ZnS exhibits not only photoluminescence [1214], but also acoustic luminescence [15], triboluminescence [16], electroluminescence $[17,18]$, and thermoluminescence [19]. One-dimensional ZnS nanostructures possess some novel properties different from their block counterpart. So far, a various of $\mathrm{ZnS}$ nanostructures including belts [20, 21], saws [22], combs and windmills [23], and fishbones [24], have been synthesized. In this paper, we reported large-scale synthesis of $\mathrm{ZnS}$ nanobelts. Au catalyst's effect on the asobtained ZnS nanostructures morphologies was discussed.
Photoluminescence properties of the as-product are also investigated.

\section{Experimental Details}

$\mathrm{ZnS}$ nanobelts were synthesized through a thermal evaporation process in a horizontal tube furnace. $1 \mathrm{~g}$ commercialgrade ZnS powder (Alfa Aesar, $99.99 \%$ purity) was placed in the center of a single-zone tube furnace and evacuated for 3 hours to purge oxygen from the chamber, then the furnace was heated $1020^{\circ} \mathrm{C}$ at a rate of $20^{\circ} \mathrm{C} / \mathrm{min}$ and keep at this temperature for $1 \mathrm{~h}$. A carrier gas of high-purity $\mathrm{Ar}$ premixed with $5 \% \mathrm{H}_{2}$ was kept flowing at a rate $50 \mathrm{sccm}$. The pressure inside the tube was maintained at 300 Torr during the whole experiment. After the furnace was cooled to room temperature, a white-yellow wool-like product was deposited on Si substrate. The collected products were characterized by a scanning electron microscope (SEM, Hitachi S-4800) equipped with an energy-dispersive X-ray detector (EDX, INCA300) and a transmission electron microscope (JEOL 


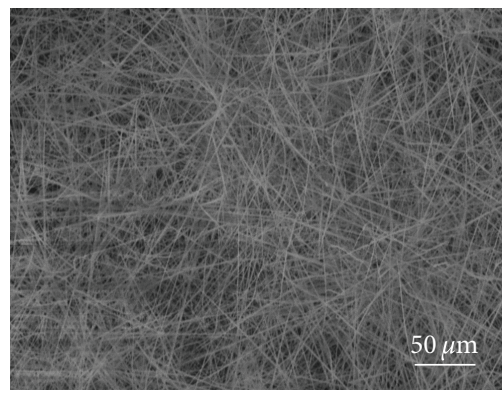

(a)

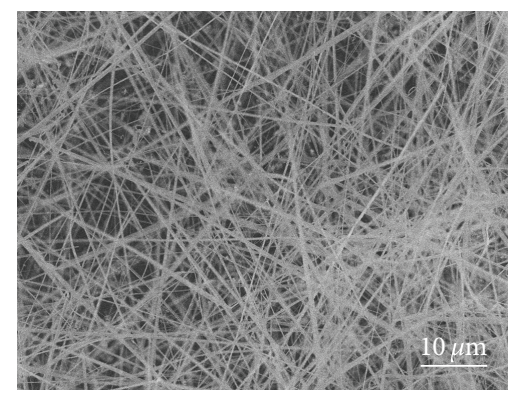

(b)

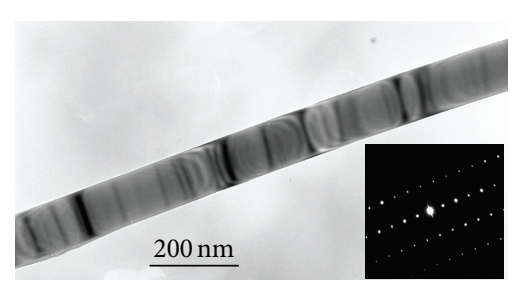

(c)

FIGURE 1: Morphology of the as-grown ZnS nanobelts (a) low magnification SEM image (b) high magnification SEM image (c) low magnification TEM image, the inset is the corresponding SAED pattern.

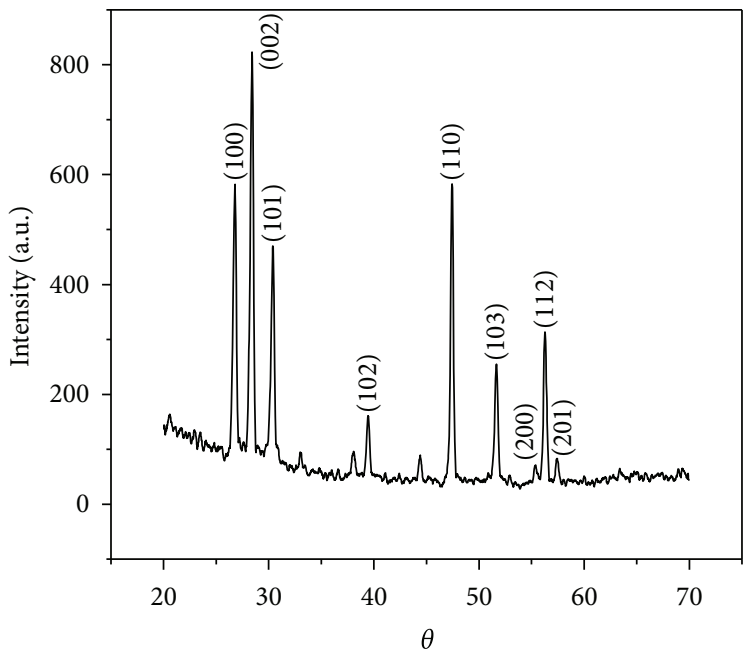

(a)

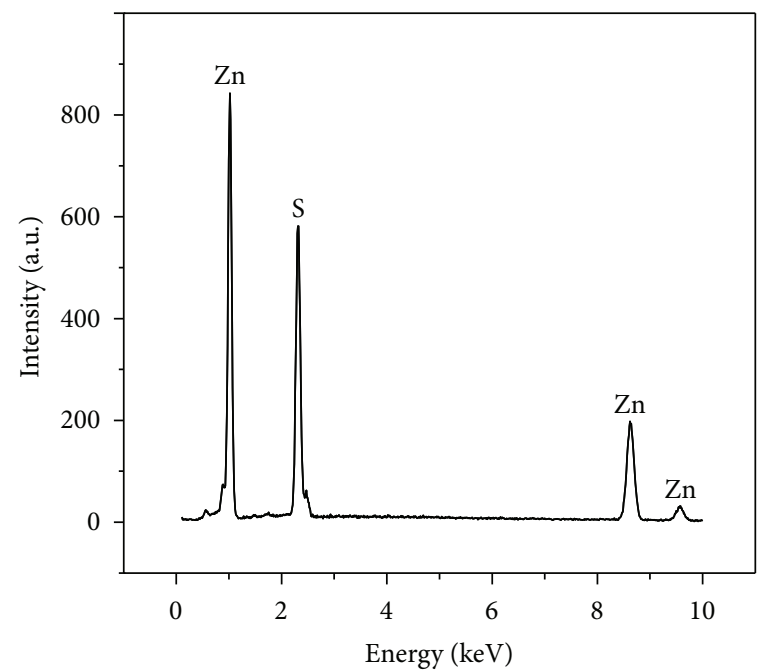

(b)

FIGURE 2: (a) XRD pattern of the as-synthesized ZnS nanobelts (b) EDS spectrum of the as-synthesized ZnS nanobelts.

JEM-2010). Photoluminescence (PL) spectra were recorded at room temperature using a $\mathrm{He}-\mathrm{Cd}$ laser with a wavelength of $325 \mathrm{~nm}$ as the excitation light source.

\section{Results and Discussion}

The general morphologies of the as-made products were examined using SEM, which were showed in Figure 1. Figure 1(a) is low magnification SEM images of $\mathrm{ZnS}$ nanobelts, one can find large quantities of wire-like structures covered on $\mathrm{Si}$ substrate. Figure 1(b) is the high magnification SEM images. Further observation found that the wirelike product present belt-like cross sections with an width of about $100 \mathrm{~nm}$ to $300 \mathrm{~nm}$ and a length of several tens of micrometers. Figure 1(c) and the insert show a typical of low magnified TEM image of the as-grown single $\mathrm{ZnS}$ nanobelt and the corresponding SAED pattern, revealing that the as-synthesized $\mathrm{ZnS}$ nanobelt possesses single crystalline structure through the entire length. $\mathrm{ZnS}$ nanobelt grows along [0001] direction.
Figure 2(a) shows XRD pattern of the as-grown products. All peaks of spectrum can be indexed to hexagonal wurtzite structure of $\mathrm{ZnS}$, with the lattice constants $a=0.382 \mathrm{~nm}$ and $c=0.626 \mathrm{~nm}$, which match well to the PDF card (no. 36-1450), without any impurities detected. Figure 2(b) is an EDS spectrum of the product, only $\mathrm{Zn}$ and $\mathrm{S}$ element are detected and $\mathrm{Zn} / \mathrm{S}$ is about $1: 1$ within experimental errors. This showed again the as-grown product of $\mathrm{ZnS}$ possess high purity.

Because Au catalyst was introduced during reaction, it is obvious that the growth mechanism of the as-grown product of $\mathrm{ZnS}$ was controlled by well-known VLS mechanism. At first, $\mathrm{ZnS}$ powder evaporated to $\mathrm{ZnS}$ vapor at high temperature, then $\mathrm{ZnS}$ vapor react with $\mathrm{H}_{2}$ to produce $\mathrm{Zn}$ and $\mathrm{H}_{2} \mathrm{~S}$ vapor, after that $\mathrm{Zn}$ vapor and $\mathrm{H}_{2} \mathrm{~S}$ vapor were carried to low temperature zone by Ar gas carrier and deposited on $\mathrm{Si}$ substrate. $\mathrm{Zn}$ and $\mathrm{Au}$ formed $\mathrm{ZnAu}$ solid solution as nuclei to absorb $\mathrm{Zn}$ vapors and $\mathrm{H}_{2} \mathrm{~S}$ vapor, where $\mathrm{Zn}$ reacts with $\mathrm{H}_{2} \mathrm{~S}$ and form $\mathrm{ZnS}$, during the whole growth process, $\mathrm{Zn}$ and $\mathrm{H}_{2} \mathrm{~S}$ continuously separated from $\mathrm{ZnAu}$ solid solution and from 


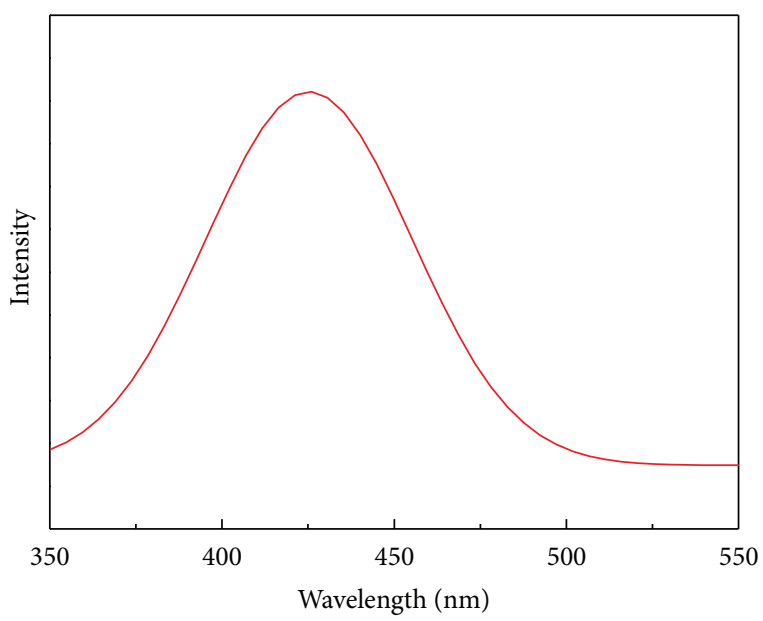

FIGURE 3: Room temperature photoluminescence spectrum of the as-synthesized $\mathrm{ZnS}$ nanobelts.

the ZnS nanobelts. However, No gold nanoparticles were found on the surface of the as-synthesized $\mathrm{ZnS}$ nanobelts, it is possible that Au particle catalysts have been evaporated when the growth of $\mathrm{ZnS}$ nanobelts finishes, which is consistent with the explanation to the growth of $\mathrm{ZnO}$ and $\mathrm{ZnGa}_{2} \mathrm{O}_{4}$ nanohelices $[25,26]$.

Figure 3 showed room temperature photoluminescence spectrum of the $\mathrm{ZnS}$ nanobelts. One can see only a stable and strong blue emission peak at $427 \mathrm{~nm}$. As known, near band edge (NBE) emission of $\mathrm{ZnS}$ should position at $337 \mathrm{~nm}$ due to combination of free excitons. Thus, the emission bands centered at $427 \mathrm{~nm}$ should be assigned to the stoichiometric vacancies or interstitial impurities in the $\mathrm{ZnS}$ nanoribbons, which has been reported by some literature $[27,28]$.

\section{Conclusion}

In summary, we have successfully synthesized wurtzite $\mathrm{ZnS}$ nanobelts in the presence of Au catalysts by thermal evaporation of $\mathrm{ZnS}$ powder at $1020^{\circ} \mathrm{C}$. The single crystalline $\mathrm{ZnS}$ nanobelts ranged from tens to hundreds of micrometers in length and hundreds of nanometers in width. Growth process may be explained by conventional VLS mechanism. Strong green emission of $\mathrm{ZnS}$ nanobelts may be attributed Au purity and high density of defects. The as-grown $\mathrm{ZnS}$ nanobelts here may be used as building blocks to fabricate various functionalized nanodevices.

\section{Acknowledgments}

This work was supported by Program for New Century Excellent Talents in Heilongjiang Provincial University (1252NCET-018).

\section{References}

[1] X. Wu, P. Jiang, Y. Ding, W. Cai, S. S. Xie, and Z. L. Wang, "Mismatch strain induced formation of $\mathrm{ZnO} / \mathrm{ZnS}$ heterostructured rings," Advanced Materials, vol. 19, pp. 2319-2323, 2007.
[2] M. Y. Lu, M. P. Lu, Y. A. Chung, M. J. Chen, Z. L. Wang, and L. J. Chen, "Intercrossed sheet-like Ga-doped $\mathrm{ZnS}$ nanostructures with superb photocatalytic activity and photoresponse," The Journal of Physical Chemistry C, vol. 113, pp. 12878-12882, 2009.

[3] H. Zeng, W. Cai, P. Liu et al., "ZnO-based hollow nanoparticles by selective etching: elimination and reconstruction of metalsemiconductor interface, improvement of blue emission and photocatalysis," ACS Nano, vol. 2, no. 8, pp. 1661-1670, 2008.

[4] X. Wu, W. Cai, and F. Y. Qu, "Tailoring morphologies and wettability property of ZnO 1D nanostructures," Acta Physica Sinica, vol. 58, pp. 8044-8049, 2009.

[5] H. B. Zeng, G. T. Duan, Y. Li, S. K. Yang, X. X. Xu, and W. P. Cai, "Blue luminescence of $\mathrm{ZnO}$ nanoparticles based on nonequilibrium process: defect origins and emission controls," Advanced Functional Materials, vol. 20, pp. 561-572, 2010.

[6] L. J. Yu, F. Y. Qu, and X. Wu, "Facile hydrothermal synthesis of novel ZnO nanocubes," Journal of Alloys and Compounds, vol. 504, pp. L1-L4, 2010.

[7] H. B. Chen, X. Wu, L. H. Gong, C. Ye, F. Y. Qu, and G. Z. Shen, "Hydrothermally-grown $\mathrm{ZnO}$ micro/nanotube arrays and their properties," Nanoscale Research Letters, vol. 5, pp. 570-575, 2010.

[8] J. Gutowski, P. Michler, H. I. Rückmann et al., "Excitons in widegap semiconductors: coherence, dynamics, and lasing," Physica Status Solidi B, vol. 234, pp. 70-83, 2002.

[9] H. C. Ong and R. P. Chang, "Optical constants of wurtzite ZnS thin films determined by spectroscopic ellipsometry," Applied Physics Letters, vol. 79, article 3612, 2001.

[10] X. C. Jiang, Y. Xie, J. Liu, L. Y. Zhu, W. He, and Y. T. Qian, "Simultaneous in situ formation of $\mathrm{ZnS}$ nanowires in a liquid crystal template by $\gamma$-irradiation," Chemistry of Materials, vol. 13, pp. 1213-1218, 2001.

[11] S. Yamaga, A. Yoshikawa, and H. Kasai, "Electrical and optical properties of donor doped $\mathrm{ZnS}$ films grown by low-pressure MOCVD," Journal of Crystal Growth, vol. 86, no. 1-4, pp. 252-256, 1990.

[12] X. Wu, J. H. Sui, W. Cai, and P. Jiang, "Temperature-Controllable Preparation of ZnS Nanosaws on Si Substrate," Chinese Physics Letters, vol. 25, pp. 737-739, 2008.

[13] W. N. Jia, B. X. Jia, X. Wu, and F. Y. Qu, "Self assembly of shape-controlled $\mathrm{ZnS}$ nanostructures with novel yellow light photoluminescence and excellent hydrophobic properties," CrystEngCommunity, vol. 14, pp. 7759-7763, 2012.

[14] S. Biswas, T. Ghoshal, S. Kar, S. Chakrabarti, and S. Chaudhuri, "ZnS nanowire arrays: synthesis, optical and field emission properties," Crystal Growth and Design, vol. 8, no. 7, pp. 2171-2176, 2008.

[15] T. V. Prevenslik, "Acoustoluminescence and sonoluminescence," Journal of Luminescence, vol. 87-89, pp. 1210-1212, 2000.

[16] C. N. Xu, T. Watannbe, M. Akiyama, and X. G. Zheng, "Preparation and characteristics of highly triboluminescent ZnS film," Materials Research Bulletin, vol. 34, pp. 1491-1500, 1999.

[17] X. Wu, Y. lei, Y. Zheng, and F. Qu, "Controlled growth and cathodoluminescence property of $\mathrm{ZnS}$ nanobelts with large aspect ratio," Nano-Micro Letters, vol. 2, pp. 272-276, 2010.

[18] J. Yan, X. Fang, L. Zhang et al., "Structure and cathodoluminescence of individual $\mathrm{ZnS} / \mathrm{ZnO}$ biaxial nanobelt heterostructures," Nano Letters, vol. 8, no. 9, pp. 2794-2799, 2008. 
[19] W. Chen, Z. G. Wang, Z. J. Lin, and L. Y. Lin, “Thermoluminescence of ZnS nanoparticles," Applied Physics Letters, vol. 70, article 1465, 3 pages, 1997.

[20] X. Fan, X. M. Meng, X. H. Zhang et al., "Dart-shaped tricrystal ZnS nanoribbons," Angewandte Chemie, vol. 45, no. 16, pp. 2568-2571, 2006.

[21] Y. Jiang, X. M. Meng, J. Liu, Z. Y. Xie, C. S. Lee, and S. T. Lee, "Hydrogen-assisted thermal evaporation synthesis of $\mathrm{ZnS}$ nanoribbons on a large scale," Advanced Materials, vol. 15, pp. 323-327, 2003.

[22] D. F. Moore, C. Ronning, C. Ma, and Z. L. Wang, "Wurtzite ZnS nanosaws produced by polar surfaces," Chemical Physics Letters, vol. 385, pp. 8-11, 2004.

[23] C. Ma, D. Moore, J. Li, and Z. L. Wang, "Nanobelts, nanocombs, and nanowindmills of wurtzite ZnS," Advanced Materials, vol. 15, pp. 228-231, 2003.

[24] X. Wu, F. Y. Qu, G. Z. Shen, and W. Cai, "Large scale synthesis of fishbone-like $\mathrm{ZnS}$ nanostructures using ITO glass as the substrate," Journal of Alloys and Compounds, vol. 482, pp. L32-L35, 2009.

[25] X. Wu, W. Cai, and F. Y. Qu, "Spontaneous formation of single crystal ZnO nanohelices," Chinese Physics B, vol. 18, pp. 1669-1773, 2009.

[26] S. Y. Bae, J. Lee, H. Jung, J. Park, and J. P. Ahn, "Helical structure of single-crystalline $\mathrm{ZnGa}_{2} \mathrm{O}_{4}$ nanowires," Journal of the American Chemical Society, vol. 127, no. 31, pp. 10802-10803, 2005.

[27] S. Kar and S. Chaudhuri, "Controlled synthesis and photoluminescence properties of $\mathrm{ZnS}$ nanowires and nanoribbons," Journal of Physical Chemistry B, vol. 109, no. 8, pp. 3298-3302, 2005.

[28] P. A. Hu, Y. Q. Liu, L. Fu, L. C. Cao, and D. B. Zhu, "Self-assembled growth of ZnS nanobelt networks," Journal of Physical Chemistry B, vol. 108, pp. 936-938, 2004. 

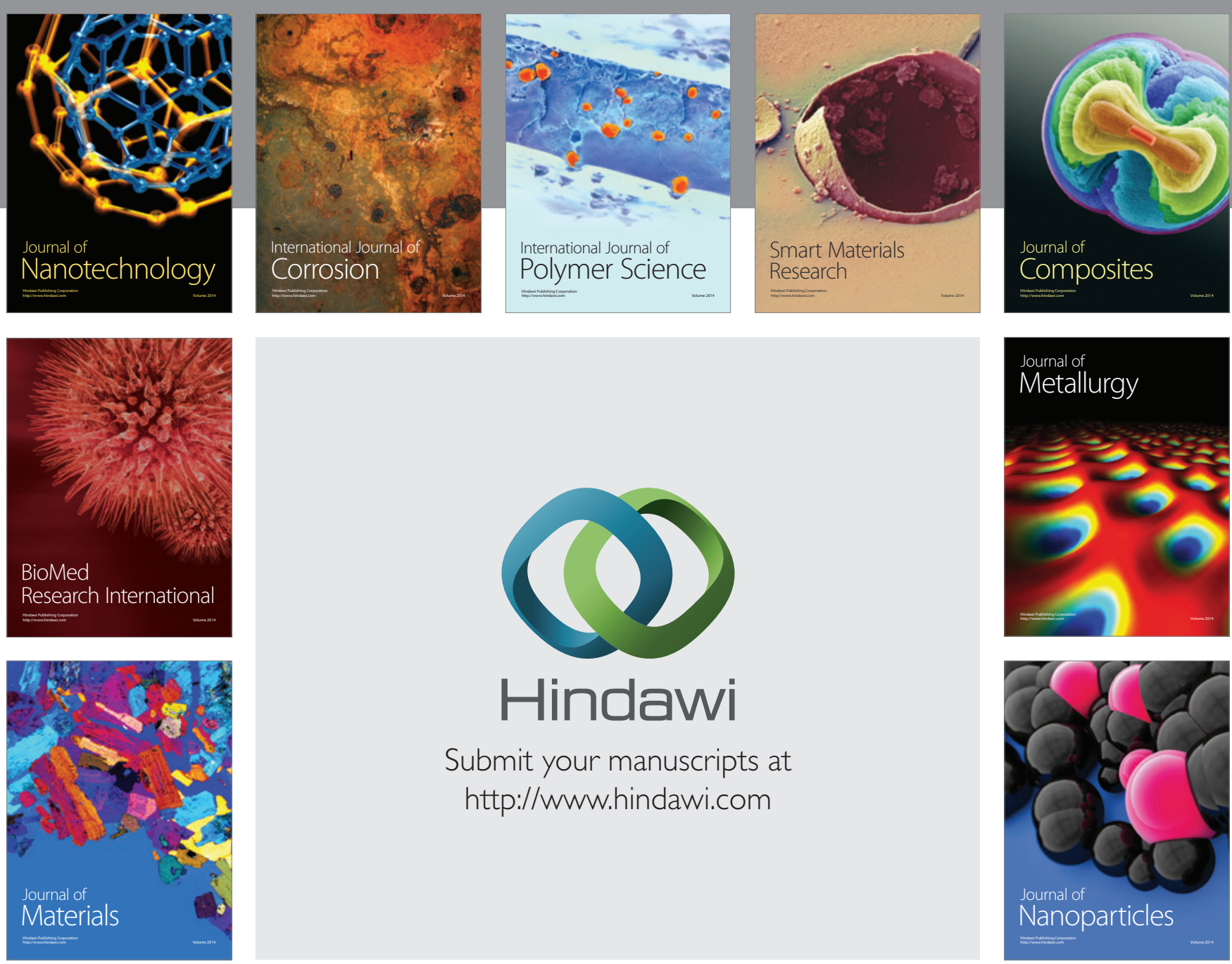

Submit your manuscripts at http://www.hindawi.com
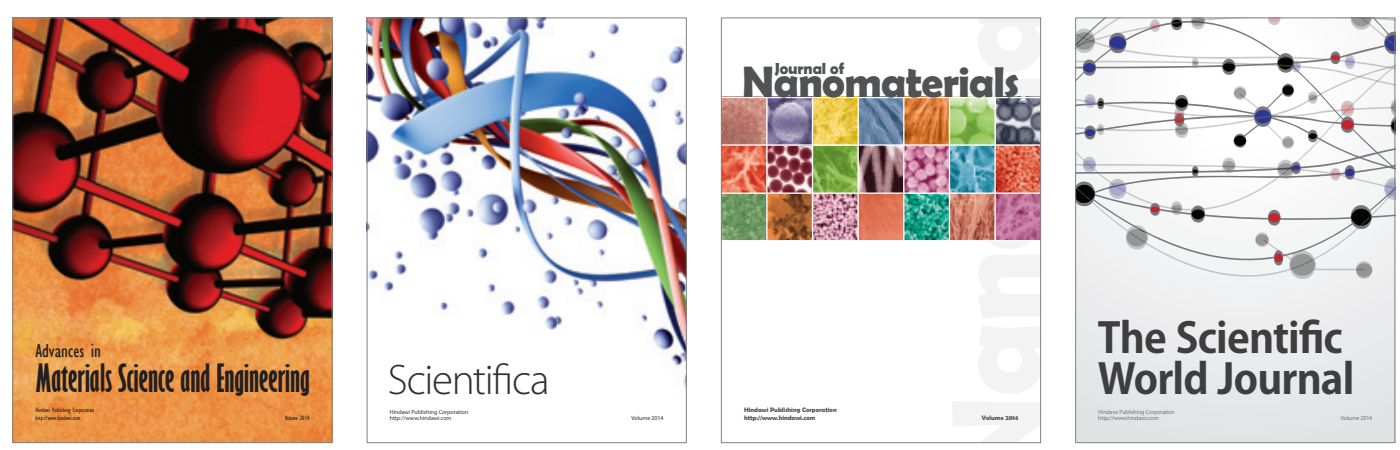

\section{The Scientific World Journal}
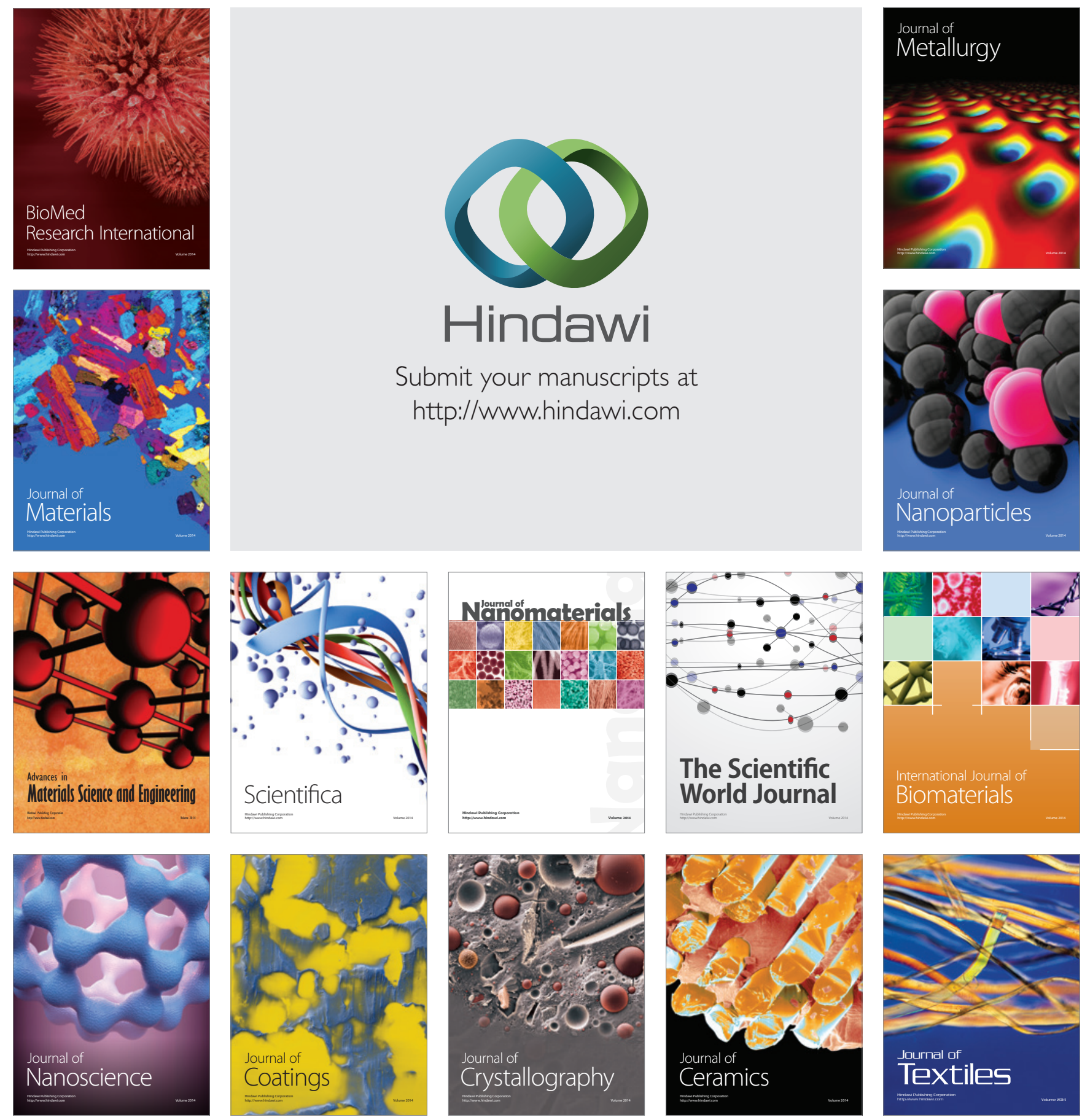